of the collaborative approach to the investigation and management of behaviours that compromise safety in National Health Service environments (Department of Health et al, 2006) and other measures should be welcomed. However, we have three concerns about the scheme described by Mann et al.

First, we are not aware of any psychiatric unit, general or of low, medium or high security, where a uniformed police officer is stationed permanently within the premises. The presence of a dedicated police officer as described by Mann et al would only bring further stigmatisation to those with mental illness who are generally perceived by the public as inherently violent. Second, most psychiatric units admit patients for assessment or treatment and the permanent presence of a police officer on site would be unsettling for many. The benefits of this approach for managing violence in a minority of patients are unlikely to outweigh the problems for the majority of patients who have never been or who may never become violent.

Third, conflicts of interest would arise if the community officer who is funded by the hospital and managed as a police officer also functions to coordinate information for defence solicitors, the Crown Prosecution Service and the police. There is a risk of compromising the fairness of the legal process for patients who behaved violently in hospital. It is important for organisations to be mindful of their approach to managing violence in order not to further stigmatise those with mental illness.

DEPARTMENT OF HEALTH, ASSOCIATION OF CHIEF POLICE OFFICERS \& HEALTH AND SAFETY EXECUTIVE (2006) Memorandum of Understanding: Investigating Patient Safety Incidents Involving Unexpected Death or Serious Untoward Harm. http://www.dh.gov.uk/en/

Publicationsandstatistics/Publications/

PublicationsPolicyAndGuidance/DH_4129918

Olumuyiwa John Olumoroti Consultant Forensic Psychiatrist, Centre for Forensic Mental Health, John Howard Centre, 12 Kenworthy Road, London E9 5TD, email: Olumuyiwa.Olumoroti@iop.kcl.ac.uk, Kayode Osanaiye Senior House Officer in Psychiatry, Kent and Medway NHS and Social Care PartnershipTrust, Gillingham, Kent

doi: 10.1192/pb.31.8.316c

\title{
obituaries
}

\section{Edmund Andrew Harvey-Smith}

\section{Formerly Consultant}

Psychiatrist, Croydon and Warlingham Group of Hospitals

The death of Eddy Harvey-Smith brings to a close the life of one of psychiatry's more colourful personalities who in the 1960s combined his love of lively debate with his fierce disapproval of the government's treatment of junior hospital doctors by chairing the Hospital Junior Staff Group Council. In this national role, Eddy fought vigorously for his colleagues to make known to the Ministry of Health and the public at large that the long hours, low pay and wretched accommodation of junior hospital doctors were unacceptable He held the post from 1963 to 1968 and during his tenure made a massive contribution to the improvement of working conditions for doctors, an improvement that his successors were able to build on in later years.

Born in 1929, Eddy attended Latymer Upper School, where he was Vice-Captain, and after National Service in the Royal Signals, he went up to St John's College, Cambridge, where he graduated MB BChir in 1956. He gained the MRCP (Lond) in 1962. The academic aspect of life appealed less - except in mild panic when exams threatened - than friendly argument and discussion, which better suited his companiable personality and his wide-ranging mind. He was also very interested in sport, specifically soccer and squash, and it was while playing soccer for St John's College that he suffered a

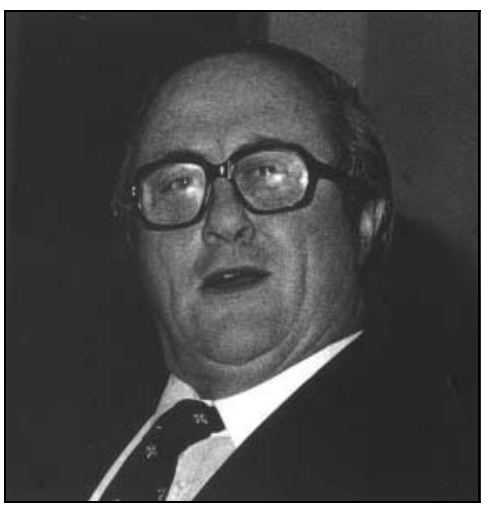

Croydon Area Health Authority. He examined for the LRCP MRCS and for many years acted as a physician for BUPA. Indeed, he preferred to think of himself as a physician with a deep interest in psychiatry. Eddy was active in establishing the Purley Day Hospital, a development that was in the vanguard of the early movement towards community care.

Eddy always enjoyed a lively relationship with his managerial colleagues. Their prime function, in his opinion, remained that of selecting the colour of the paint. His withering wit also translated itself magnificently to a prodigious output of correspondence, which not infrequently found its way into the national press and the Secretary of State for Health's private office.

After retirement from the NHS in 1994 he continued to do locum work and see patients privately well into his seventies. It was at Hayes Grove Priory Hospital that his irreverence for authority came to the fore. His discussion groups over the lunch table, followed by a game of pool, and his tendency to see an occasional patient in the garden provoked a vocal response from management who did not care to have their hospital treated as a country club.

His later years were clouded by the onset of dementia and he was lovingly cared for at home by his daughter,

Caroline and two sons, Andrew and Mark, until he had to move across the road to Kingston Hospital. 'I'm afraid it's

Alzheimer's, old boy,' he observed in one of his lucid moments.

He died on 28 January 2007 and will be sorely missed.

\section{A. J. Watson}

doi: 10.1192/pb.bp.107.016667 26 years. Pursuing his political interests he and on the Medical Executive SubCommittee from 1985 to 1990, and was the Consultant Representative on the

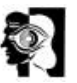

columns 